CLINICAL STUDY

\title{
Counterregulatory responses to hypoglycemia in patients with maturity-onset diabetes of the young caused by HNF-1 $\alpha$ gene mutations (MODY3)
}

\author{
E Guenat ${ }^{1}$, G Seematter $^{1}$, J Philippe ${ }^{2}$, E Temler $^{3}$, E Jéquier $^{1}$ and L Tappy ${ }^{1}$ \\ ${ }^{1}$ Institut de Physiologie, Université de Lausanne, ${ }^{2}$ Division d'Endocrinologie et Diabétologie, Hôpital Cantonal Universitaire, Genèva and ${ }^{3}$ Division \\ d'Endocrinologie, Diabète et Métabolisme, CHUV, Lausanne, Switzerland \\ (Correspondence should be addressed to L Tappy, Institut de Physiologie, 7 rue du Bugnon, CH-1005 Lausanne; Email: Luc.Tappy@iphysiol.unil.ch)
}

\begin{abstract}
Mutations of HNF-1 $\alpha$ lead to severe $\beta$ cell dysfunction, resulting in decreased glucose-induced insulin secretion. HNF-1 $\alpha$ is also expressed in liver, kidney and pancreatic $\alpha$ cells, but the functional consequences of HNF-1 $\alpha$ mutations in these organs remain unknown. We therefore assessed the counterregulatory responses to hypoglycemia in six patients with HNF-1 $\alpha$ mutations (MODY3), five patients with non-insulin-dependent diabetes mellitus (NIDDM) and in nine healthy controls. Plasma glucagon concentrations and endogenous glucose production were measured every 15 min during a hyperinsulinemic clamp with progressive hypoglycemia. Plasma glucagon concentrations were similar at basal glycemia $(73 \pm 6,69 \pm 5$ and $69 \pm 7 \mathrm{ng} / \mathrm{l})$ and reached peak values of $88 \pm 9$, $88 \pm 11$ and $89 \pm 7 \mathrm{ng} / \mathrm{l}$ at a glycemia of $3.6 \mathrm{mmol} / \mathrm{l}$ in MODY3 patients, patients with NIDDM and controls respectively (NS). Suppression of endogenous glucose production by insulin was blunted in MODY 3 patients $(3.3 \pm 1.2 \mu \mathrm{mol} / \mathrm{kg}$ per min) and in patients with NIDDM $(4.4 \pm 0.6 \mu \mathrm{mol} / \mathrm{kg}$ per min) compared with controls $(1.7 \pm 0.5 \mu \mathrm{mol} / \mathrm{kg}$ per min, $P<0.05$ compared with both MODY 3 patients and patients with NIDDM). During hypoglycemia, endogenous glucose production increased to $8.6 \pm 2.1,8.8 \pm 0.7$ and $7.0 \pm 1.0 \mu \mathrm{mol} / \mathrm{kg}$ per min in MODY3 patients, patients with NIDDM and controls respectively (all NS). These data indicate that mutations of HNF-1 $\alpha$ in MODY3 do not result in a decreased glucagon secretion or alterations of glucose production during hypoglycemia.
\end{abstract}

European Journal of Endocrinology 144 45-49

\section{Introduction}

Diabetes mellitus is a group of disorders of various etiological causes and pathophysiological mechanisms. Physiological and clinical studies indicate that hyperglycemia can develop as the result of decreased insulin secretion, insulin resistance, or defective neuroendocrine control of glucose homeostasis at the level of the central nervous system (1-4). One or several of these factors may therefore be involved in the development of impaired glucose tolerance or diabetes mellitus.

Maturity onset diabetes of the young 3 (MODY3) is a subtype of diabetes mellitus secondary to mutations of the hepatocyte nuclear factor $1 \alpha$ (HNF-1 $\alpha$ ) gene (5). It is characterized by the development of a severe impairment of insulin secretion in response to various secretagogues in early adulthood $(6,7)$ as a result of HNF- $1 \alpha$ mutations in pancreatic $\beta$ cells. Defective insulin secretion has also been observed in HNF-1 $\alpha$ deficient mice, supporting the concept that insulin deficiency is responsible for the development of diabetes in patients with HNF-1 $\alpha$ mutations (8). In contrast, insulin sensitivity has been reported to be essentially normal or mildly decreased $(6,9)$ in MODY 3 patients. This minor impairment of insulin action is presumably secondary to the effects of chronic hyperglycemia (10), as the HNF-1 $\alpha$ gene is not expressed in skeletal muscle, the major tissue that determines insulin sensitivity.

HNF-1 $\alpha$ is also expressed in liver, kidney and pancreatic $\alpha$ cells (11), but little information is available regarding the consequences of HNF- $1 \alpha$ mutations in these cells. In liver and kidney cells, mutations of HNF-1 $\alpha$ may be expected to affect glucose production. Arginine-induced glucagon secretion is impaired in MODY 3 patients, suggesting that HNF-1 $\alpha$ leads to functional alterations of pancreatic $\alpha$ cells (12). Alterations of glucose production and glucagon secretion secondary to HNF-1 $\alpha$ mutations may possibly play a part in the development of hyperglycemia or impair the counterregulatory responses to hypoglycemia in MODY3 patients.

To assess further the consequences of HNF- $1 \alpha$ mutations on liver and pancreatic $\alpha$ cells, we measured endogenous glucose production and the concentrations 
of counterregulatory hormones during moderate hyperinsulinemia with a progressive decrease in plasma glucose concentrations in a group of MODY3 patients and in a group of healthy volunteers. In order to evaluate the possible effects of chronic hyperglycemia, the same parameters were also measured in a small group of patients with non-insulin-dependent diabetes mellitus (NIDDM).

\section{Methods}

\section{Patients}

Six MODY3 patients (three men, three women), five patients with NIDDM (one man, four women) and 10 healthy individuals (five men, five women) were recruited to participate in this study. Their characteristics are shown in Table 1. A genetic analysis was performed after DNA extraction from peripheral blood samples. Screening for mutations in the HNF-1 $\alpha$ gene was performed by PCR, amplification of each exon and direct sequencing of the PCR product (5). Five patients from the same family (13) had a frameshift mutation (C deletion in codon 291 of exon 4). The sixth patient had a frameshift mutation (C insertion in codon 291 of exon 4). The experimental procedure in which the patients and healthy individuals agreed to participate had been approved by the Ethics committee of Lausanne University School of Medicine, and every participant provided an informed, written consent.

\section{Experimental protocol}

The experiments began between $0700 \mathrm{~h}$ and $0800 \mathrm{~h}$. The participants had been fasting since $2200 \mathrm{~h}$ the previous day. Oral antidiabetic medications had been discontinued for 72 hours, and insulin treatments for 24 hours.

On their arrival at the metabolic laboratory, each individual was weighed and measured. Thereafter they rested quietly in bed during the entire experiments, while watching video movies. One cannula was inserted into an antecubital vein of the left arm for infusion of insulin, glucose, and $6,6-\left[{ }^{2} \mathrm{H}\right]$ glucose. A second cannula was inserted into a wrist vein of the right arm for blood sampling. The right hand was placed in a thermostabilized box heated to $56{ }^{\circ} \mathrm{C}$ to achieve partial arterialization of venous blood. In MODY3 patients, a primed-continuous infusion of insulin $(2.4 \mathrm{pmol} / \mathrm{kg}$ per min) was started at time 0 (14), and variable infusion of $20 \%$ dextrose was administered to maintain plasma glucose at basal values until time 120 min. Dextrose infusion was then reduced until plasma glucose could be maintained at $5 \mathrm{mmol} / \mathrm{l}$ during a period of $30 \mathrm{~min}$. Thereafter, dextrose infusion was gradually reduced to decrease the plasma glucose concentrations by $0.5 \mathrm{mmol} / \mathrm{l}$ every $30 \mathrm{~min}$ until a plasma glucose concentration of $3.6 \mathrm{mmol} / \mathrm{l}$ was reached. In healthy controls, the experimental procedure was identical, except that basal glucose concentrations were maintained until $180 \mathrm{~min}$ to minimize the differences in duration of insulin infusions between MODY3 patients and patients with NIDDM and healthy controls at each glucose concentration step. During the entire procedure, the dextrose infused was mixed with $1.25 \% \quad 6,6-\left[{ }^{2} \mathrm{H}\right] \mathrm{glu}-$ cose (Masstrace, Worcester, MA, USA) to measure glucose kinetics using the 'hot infusate' model (15). An infusion of $0.14 \mu \mathrm{mol} / \mathrm{kg}$ per min $6,6-\left[{ }^{2} \mathrm{H}\right]$ glucose was maintained when dextrose infusion was less than $11 \mu \mathrm{mol} / \mathrm{kg}$ per min. Two blood samples were collected 15 min apart at each plateau of glycemia.

\section{Analytical procedures}

Plasma glucose was measured using a Beckman glucose analyzer II (Beckman Instruments, Fullerton, CA, USA). Plasma insulin (kit from Biodata, Guidonia Montecello, Italy), glucagon (kit from Linco Research, St Charles, MO, USA), and cortisol (kit from Diagnostic Products Corporation, Los Angeles, CA, USA) were measured by radioimmunoassays. Plasma growth hormone concentrations were measured by a chemiluminescence immunometric assay (Nichols Institute,

Table 1 Characteristics of the participants. Values are numbers or means \pm S.D.

\begin{tabular}{|c|c|c|c|c|c|c|c|}
\hline Participant & Sex & Age (yr) & Weight (kg) & Height (m) & Treatment & $\mathrm{HbA}_{1 \mathrm{c}}(\%)$ & Diabetes duration (yr) \\
\hline \multicolumn{8}{|l|}{ MODY3 patients } \\
\hline 1 & $\mathrm{~F}$ & 32 & 71 & 1.62 & $\begin{array}{l}\text { Glimepiride } \\
\text { Metformin }\end{array}$ & 8.8 & 8 \\
\hline 2 & $\mathrm{~F}$ & 51 & 53 & 1.52 & Insulin & 9.7 & 26 \\
\hline 3 & $\mathrm{M}$ & 32 & 74 & 1.71 & Diet & 7.2 & 7 \\
\hline 4 & $\mathrm{M}$ & 31 & 68 & 1.75 & Diet & 7.2 & 6 \\
\hline 5 & $\mathrm{M}$ & 27 & 92 & 1.72 & Diet & 10.8 & 4 \\
\hline \multirow[t]{2}{*}{6} & $\mathrm{~F}$ & 20 & 57 & 1.80 & Glibenclamide & 7.4 & 1 \\
\hline & $3 \mathrm{~F} / 3 \mathrm{M}$ & $32 \pm 10$ & $69.1 \pm 13.8$ & $1.68 \pm 0.10$ & & & \\
\hline NIDDM patients & $1 \mathrm{~F} / 4 \mathrm{M}$ & $53 \pm 3$ & $82.4 \pm 8.4$ & $1.69 \pm 0.07$ & Insulin $(n=5)$ & $8.8 \pm 0.3$ & $8 \pm 4$ \\
\hline Healthy individuals & $5 \mathrm{~F} / 5 \mathrm{M}$ & $42 \pm 9$ & $65.5 \pm 12.6$ & $1.70 \pm 0.11$ & & - & - \\
\hline
\end{tabular}

$\mathrm{HbA}_{1 \mathrm{c}}$, glycated hemoglobin. 
San Juan Capistrano, CA, USA). Plasma epinephrine and norepinephrine concentrations were measured by HPLC with electrochemical detection (16). Plasma 6,6$\left.{ }^{2} \mathrm{H}\right]$ glucose was measured with gas chromatographymass spectrometry as described elsewhere (17).

\section{Calculations}

Glucose rates of appearance (GRa) and disappearance (GRd) were calculated from 6,6- $\left[{ }^{2} \mathrm{H}\right]$ glucose dilution analysis using the hot infusate model (15). Endogenous glucose production was calculated by subtracting dextrose infusion from GRa. Glycemic thresholds for secretion of counterregulatory hormone were determined as the first glucose concentration at which each hormone was statistically increased compared to values obtained at basal glycemia.

\section{Statistical analysis}

All results in text, tables and figures are shown as mean \pm 1 s.E.M. unless stated otherwise. Comparisons between MODY 3 and patients with NIDDM and healthy individuals were made using MANOVA and unpaired $t$-tests with Bonferroni's correction. Determination of individual glycemic thresholds for counterregulatory hormones secretion and stimulations of glucose production were assessed by determining, by means of $t$-tests, the first level of glycemia at which hormone concentrations increased significantly compared to euglycemia. The statview 4.5 statistical package (Abbacus Concepts, Berkeley, CA, USA) was used for these calculations.

\section{Results}

Fasting plasma glucose concentration was increased in MODY3 patients $(10.4 \pm 1.9 \mathrm{mmol} / \mathrm{l}, P<0.01)$ and in patients with NIDDM $(12.4 \pm 2.3 \mathrm{mmol} / \mathrm{l}, P<0.001)$ compared with healthy controls $(5.2 \pm 0.1 \mathrm{mmol} / \mathrm{l})$. Fasting plasma insulin concentrations were modestly increased in patients with NIDDM $(102 \pm 32 \mathrm{pmol} / \mathrm{l})$ compared with MODY3 patients ( $58 \pm 13 \mathrm{pmol} / \mathrm{l})$ and healthy individuals $(52 \pm 7 \mathrm{pmol} / \mathrm{l})$. Insulin infusion resulted in plasma insulin concentrations of $205 \pm 20$, $281 \pm 35$ and $210 \pm 19 \mathrm{pmol} / \mathrm{l}$ (NS) in MODY3 patients, patients with NIDDM and healthy individuals respectively.

During the initial period of insulin infusion, plasma glucose concentrations were maintained at each individual's basal values. Counterregulatory hormones concentrations during this period were not different in the three groups (Fig. 1). Endogenous glucose production was greater in both MODY3 and patients with NIDDM than in healthy individuals, and GRd was lower only in patients with NIDDM (Table 2).

During the second period of insulin infusion, plasma glucose concentrations was allowed to decrease progressively by reducing the rate of exogenous glucose infusion. The evolution of counterregulatory hormone
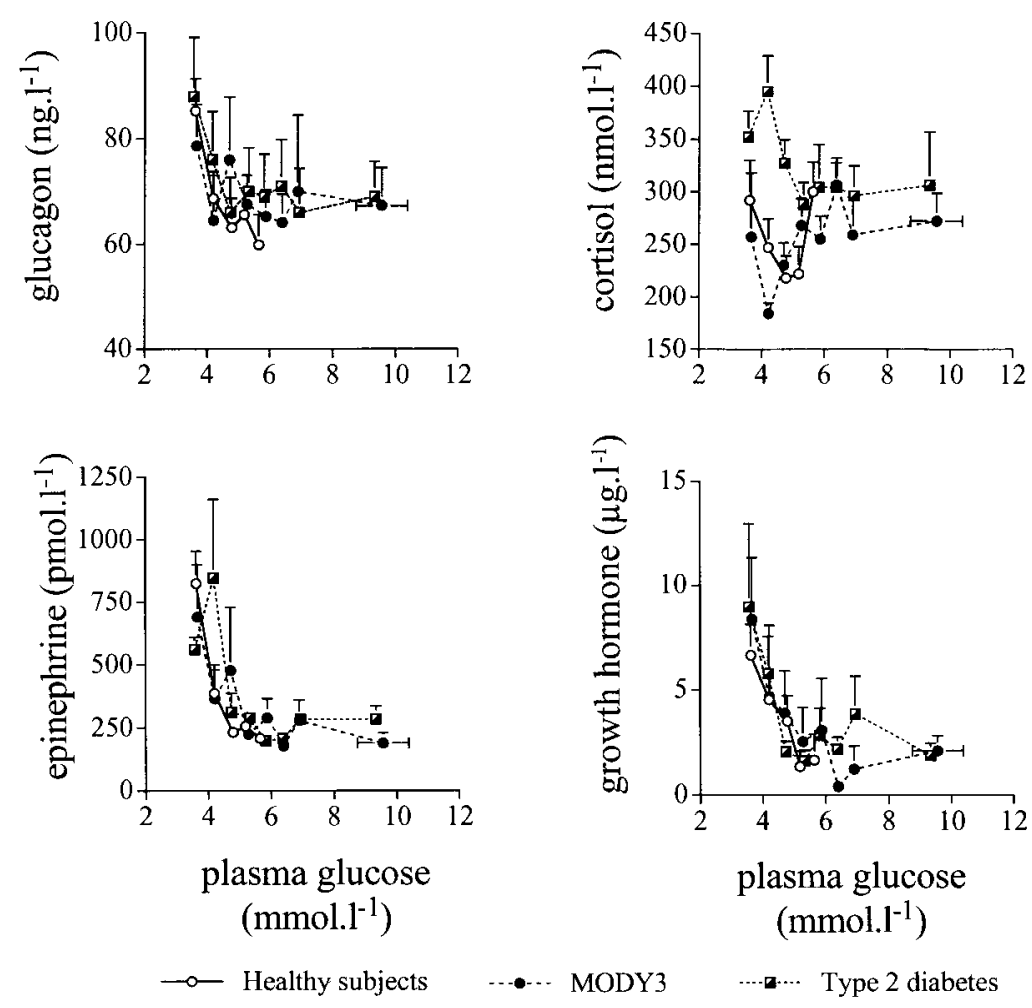

Figure 1 Counterregulatory hormone concentrations as a function of glycemia in MODY3 patients, patients with NIDDM and healthy individuals. 
Table 2 Endogenous glucose production ( $\mu \mathrm{mol} / \mathrm{kg}$ per $\mathrm{min}$ ) and glucose rate of disappearance ( $\mu \mathrm{mol} / \mathrm{kg}$ per $\mathrm{min}$ ) during hyperinsulinemia at basal glycemia and at hypoglycemia.

\begin{tabular}{lrc}
\hline & $\begin{array}{c}\text { Basal } \\
\text { glycemia }\end{array}$ & Hypoglycemia \\
\hline MODY3 & & \\
$\quad$ Endogenous glucose production & $3.3 \pm 1.2^{*}$ & $8.6 \pm 2.1$ \\
$\quad$ Glucose rate of disappearance & $17.8 \pm 2.7$ & $21.3 \pm 1.6$ \\
NIDDM & & \\
$\quad$ Endogenous glucose production & $4.4 \pm 0.6^{*}$ & $8.8 \pm 0.7$ \\
$\quad$ Glucose rate of disappearance & $12.4 \pm 1.3^{*}$ & $9.6 \pm 1.0^{*}$ \\
Healthy individuals & & \\
$\quad$ Endogenous glucose production & $1.7 \pm 0.5$ & $7.0 \pm 1.0$ \\
$\quad$ Glucose rate of disappearance & $24.4 \pm 2.0$ & $16.2 \pm 1.2$ \\
\hline
\end{tabular}

${ }^{*} P<0.05$ compared with healthy individuals

concentrations as a function of glycemia is shown in Fig. 1. Stimulation of counterregulatory hormone secretion by hypoglycemia and the glycemic threshold at which each hormone increased significantly were not different in MODY3 patients compared with patients with NIDDM and healthy controls (Fig. 1, Table 3). Endogenous glucose production at the final glycemia of $3.6 \mathrm{mmol} / \mathrm{l}$ was also similar in all groups of patients, but GRd was lower in patients with NIDDM (Table 2).

\section{Discussion}

HNF- $1 \alpha$ is highly expressed in the liver and kidneys. As these two organs are responsible for endogenous glucose production (18), and as increased glucose production may participate in the pathogenesis of hyperglycemia, it was of interest to determine whether mutations of HNF-1 $\alpha$ led to dysregulation of glucose production. Our previous data indicated that MODY3 patients have normal basal glucose production rates (9). However, as hyperglycemia suppresses glucose production (17), the normal glucose production in MODY3 patients may in fact be considered to be abnormally increased. In contrast, the modest hyperinsulinemia elicited by infusion of $2.4 \mathrm{nmol} / \mathrm{kg}$ per min insulin efficiently suppressed glucose production, which confirms the results of a previous study (9). Compared with that in healthy individuals, the insulin-mediated suppression of glucose production in MODY3 patients

Table 3 Glycemic thresholds ( $\mathrm{mmol} / \mathrm{l}$ ) for counterregulatory hormone secretion and for increase in endogenous glucose production.

\begin{tabular}{lcccc}
\hline & Glucagon & Epinephrine & $\begin{array}{c}\text { Growth } \\
\text { hormone }\end{array}$ & Cortisol \\
\hline MODY3 & $4.0 \pm 0.2$ & $3.7 \pm 0.3$ & $3.8 \pm 0.3$ & $3.2 \pm 0.1$ \\
NIDDM patients & $4.1 \pm 0.1$ & $3.5 \pm 0.1$ & $4.2 \pm 0.2$ & $4.1 \pm 0.2$ \\
Controls & $3.6 \pm 0.1$ & $3.8 \pm 0.2$ & $4.2 \pm 0.2$ & $3.8 \pm 0.2$ \\
\hline
\end{tabular}

was, however, significantly impaired and was similar to that observed in patients with NIDDM. MODY3 patients had a slight, non-significant decrease in insulinmediated glucose disposal. This corroborates our earlier observation that insulin sensitivity is not markedly decreased in this subtype of MODY (9). In contrast, patients with NIDDM had a significant decrease in insulin-mediated glucose disposal, indicating insulin resistance. This may be attributed, at least in part, to their greater body weight.

The glycemic threshold at which glucose production started to increase and the absolute values of glucose production at a glycemia of $3.6 \mathrm{mmol} / \mathrm{l}$ were similar in MODY 3 patients, in patients with NIDDM and in healthy controls. Taken together, these data indicate that the control of glucose production was only modestly altered in MODY3 patients. Furthermore, as similar alterations were observed in patients with NIDDM, they suggest that these alterations may be essentially secondary to the effect of chronic hyperglycemia and glucose toxicity (10). Thus our data do not support the hypothesis of major alterations of hepatic or renal glucose production as a direct consequence of HNF- $1 \alpha$ mutations.

HNF- $1 \alpha$ is also expressed in pancreatic $\alpha$ cells, and an impaired arginine-induced glucagon secretion has been observed in patients with HNF-1 $\alpha$ mutations (12) or with HNF-4 $\alpha$ (19). This raised the possibility that impaired glucagon release may place these patients at an increased risk of severe insulin-induced hypoglycemia. Our present data however indicate that glucagon secretion was not impaired in MODY3 patients during hypoglycemia. These results therefore do not support the hypothesis of an impaired counterregulatory response to hypoglycemia in MODY3. Our experimental procedure, however, produced only a moderate hypoglycemia, which does not permit us to undertake a quantitative evaluation of the amplitude of counterregulatory hormone responses in the different groups tested. The insulin infusion rate used in this study also produced modest hyperinsulinemia, and the ability of MODY3 patients to reverse the inhibition of glucose production during hypoglycemia at greater plasma insulin concentrations cannot be evaluated from our data.

In conclusion, our data indicate that mutations of HNF- $1 \alpha$ do not result in abnormal counterregulatory responses to hypoglycemia. Suppression of endogenous glucose production by insulin is mildly impaired in MODY3 patients. This may however be secondary to chronic hyperglycemia, as similar alterations are observed in patients with NIDDM.

\section{Acknowledgements}

This work was supported by a grant from the Swiss National Science Foundation (No. 32-56700.99). 


\section{References}

1 Gerich JE. Control of glycaemia. Baillière's Clinical Endocrinology and Metabolism 19937 551-586.

2 DeFronzo RA. The triumvirate: $\beta$-cell, muscle, liver. A collusion responsible for NIDDM. Diabetes 198837 667-687.

3 Jeanrenaud B, Halimi S \& Van de Werve G. Neuroendocrine disorders seen as triggers of the triad: obesity-insulin resistanceabnormal glucose tolerance. Diabetes/Metabolism Reviews 19851 261-291.

4 Tappy L. Regulation of hepatic glucose production in healthy subjects and in NIDDM. Diabète et Métabolisme (Paris) 199521 233-240.

5 Yamagata K, Oda N, Kaisaki PJ, Menzel S, Furuta H, Vaxillaire $\mathrm{M}$ et al. Mutations in the hepatocyte nuclear factor$1 \alpha$ gene in maturity-onset diabetes of the young (MODY3). Nature $1996 \mathbf{3 8 4} 455-458$.

6 Lehto M, Tuomi T, Mahtani MM, Widén E, Forsblom C, Sarelin L et al. Characterization of the MODY3 phenotype. Early-onset diabetes caused by an insulin secretion defect. Journal of Clinical Investigation 199799 582-591.

7 Byrne MM, Sturis J, Menzel S, Yamagata K, Fajans SS, Dronsfield MJ et al. Altered insulin secretory responses to glucose in diabetic and nondiabetic subjects with mutations in the diabetes susceptibility gene MODY3 on chromosome 12. Diabetes 199645 1503-1510.

8 Pontoglio M, Sreenan S, Roe M, Pugh W, Ostrega D, Doyen A et al. Defective insulin secretion in hepatocyte nuclear factor 1 alpha-deficient mice. Journal of Clinical Investigation 1998101 2215-2222.

9 Surmely JF, Guenat E, Philippe J, Dussoix P, Schneiter P, Temler E et al. Glucose utilization and production in patients with maturity-onset diabetes of the young caused by a mutation of the hepatocyte nuclear factor- $1 \alpha$ gene. Diabetes $1998 \mathbf{4 7}$ 1459-1463.

10 Yki-Järvinen H. Glucose toxicity. Endocrine Reviews 199213 415-431.

11 Froguel P \& Velho G. Molecular genetics of maturity-onset diabetes of the young. Trends in Endocrinology and Metabolism $199910142-146$.
12 Yoshiuchi I, Yamagata K, Yang Q, Iwahashi H, Okita K, Yamamoto $\mathrm{K}$ et al. Three new mutations in the hepatocyte nuclear factor-1alpha gene in Japanese subjects with diabetes mellitus: clinical features and functional characterization. Diabetologia 199942 621-626.

13 Vaxillaire M, Rouard M, Yamagata K, Oda N, Kaisaki PJ, Boriraj VV et al. Identification of nine novel mutations in the hepatocyte nuclear factor 1 alpha gene associated with maturityonset diabetes of the young (MODY3). Human Molecular Genetics 19976 583-586.

14 DeFronzo RA, Tobin JD \& Andres R. Glucose clamp technique: a method for quantifying insulin secretion and resistance. American Journal of Physiology 1979237 E214-E223.

15 Finegood DT, Bergman RN \& Vranic M. Estimation of endogenous glucose production during hyperisulinemic glucose clamps: comparison of labelled and unlabelled glucose infusates. Diabetes $198736914-924$.

16 Hallman J, Farnebo LO, Hamberger B \& Jonsson G. A sensitive method for determination of plasma catecholamines using liquid chromatography with electrochemical detection. Life Sciences 197823 1049-1052.

17 Tappy L, Dussoix P, Iynedjian P, Henry S, Schneiter P, Zahnd G et al. Abnormal regulation of hepatic glucose output in maturity onset diabetes of the young caused by a specific mutation of the glucokinase gene. Diabetes 199746 204-208.

18 Stumvoll M, Meyer C, Mitrakou A, Nadkarni V \& Gerich JE. Renal glucose production and utilization: new aspects in humans. Diabetologia 199740 749-757.

19 Herman WH, Fajans SS, Smith MJ, Polonsky KS, Bell GI \& Halter JB. Diminished insulin and glucagon secretory responses to arginine in nondiabetic subjects with a mutation in the hepatocyte nuclear factor-4a/MODY1 gene. Diabetes I 199746 $1749-1754$.

Received 20 June 2000

Accepted 6 September 2000 